\title{
Fisioterapia, Neurologia e Filosofia
}

\section{Physiotherapy, Neurology and Philosophy}

\author{
Luís Filipe dos Santos Coelho ${ }^{1 *}$
}

PALAVRAS-CHAVE: Especialidade de Fisioterapia; Filosofia; Modalidades de Fisioterapia; Neurologia

KEYWORDS: Neurology; Philosophy; Physical Therapy Modalities; Physical Therapy Specialty

Compreender, epistemologicamente, o produto (fisio) terapêutico é fundir, necessariamente, os objetos clínico e filosófico numa unidade substancialmente neural que deveria ser mais frequentemente recrutada. De facto, toda a fisioterapia é neurológica, no equilíbrio que ela consigna e no desenlace que proporciona.

Avocando o paralelismo entre espírito e corpo, mente e "physis", dialética e positividade, raciocínio e experimentalidade, a polaridade entre os evocados cria a dor, enquanto principal expressão clínica. Se o objetivo "função indolor" é supremo, subsistir um hiato entre movimento e estrutura insofrida demonstra, mais uma vez, o défice de equilíbrio, de obrigatório monismo identitário.

No corpo, a zona posterior, "anti-gravítica", repleta de músculos de ativação fortemente inconsciente, repre- senta o quadrante hipertónico, cujo bom funcionamento indolor depende da reposição da flexibilidade (neuro) miofascial. A sua defesa é, isomorficamente, hipertónica, na medida em que sistemas grandemente teoréticos e abstratos, como os baseados na reeducação postural ${ }^{1-3}$ ou no Conceito Bobath, ${ }^{4}$ são de expressão mormente dogmática, muito apoiados na observação de carácter subjetivo, tão demonizada pelo modelo baconiano. ${ }^{5}$ Segundo os paradigmas em questão, a função articular "normal" só poderá ser obviada pelo alongamento adequado das cadeias miofasciais, pela inibição da tensão excessiva. Jaz o alicerce teorético segundo o qual o estado da articulação depende fortemente das condições de postura e alinhamento. Assim, a par da demonização do trabalho de força, sobretudo da zona posterior já demasiado "forte" (porque constituída, principalmente, por 
músculos com função postural e de fácil encurtamento, e que nunca relaxam por inteiro ${ }^{6}$ ), o alongamento insuficiente, bem como o excessivo, faz por perpetuar o jogo de "deformações". O segundo referido poderá originar defesas ou compensações, expressadas empiricamente pela "dor". Esta pode ser, também, suscitada pela identicamente demonizável "higiene postural", que faz por reforçar conscientemente estruturas essencialmente inconscientes e tónicas.

O alongamento exagerado, o descomedimento na prescrição do paradigma, exprime, assim, a manifestação sintomática, que o mesmo seria dizer que o paciente reage ao excesso do seu terapeuta. Este é um exceder moral, com que o paciente pode reagir compensatoriamente com renovada moral empírica, novel postura, capaz de renovar o objeto da função indolor. A resultante implica muito mais do que um certo comprimento muscular, é, a bem ver, um carácter da postura, essencialmente neurológico, que exprime a adequação da (i)razão descendente à sensitização ascendente, da vontade "agente" à pretérita paciência empírica. Este é, portanto, o equilíbrio monístico em que a sensação produz a razão, o movimento delineia a posição e a função arquiteta o alinhamento, a verticalização do intrínseco ráquis, que "ascende" espiritualmente em confronto e síntese com a realidade, produzindo o "Ser", que é normativizar, totalizar, a dimensão clínica, que não deixa de exprimir uma dicotomia, bem como a visão fragmentária do próprio corpo. Esta vertente dual é reguladora, o estado de "Ser" é a nova normalidade, se bem que reificada pela realidade. Porque o equilíbrio não pode deixar de compatibilizar o objeto do "insofrimento" agente com o princípio da realidade percipiente, que o mesmo é dizer que se equilibram terapeuta e paciente num trajeto "vitalista" que destrona consecutivamente a visão clínica fragmentária, tendencialmente dogmática, em nome de uma holisticidade sana.

O potencial holístico integra a realidade clínica na novidade contínua duma patonormatividade neural, postural, heurística, que se obtém crescentemente pela ação espontânea, individuadora, sintetizadora, de um "Eu" aberto à relação e eticamente desvelado. Tal objeto dispensa a prescrição dogmática, potenciando o movimento, a força, que, agora, pode ser livremente trabalhado pelo paciente-agente. A potência manifesta liberta-se naturalmente duma estrutura flexível.

Obviamente, uma postura funcionante poderá implicar uma descompensação para outrem, do mesmo modo que um terapeuta se pode placebetizar à custa do desequilíbrio do paciente, ou que uma psique adequada pode desadequar uma "physis", mas isto é assumir, mais uma vez, a necessidade de uma harmonia neural funcional e criadora que permita urdir inúmeras possibilidades de "Ser".

\section{RESPONSABILIDADES ÉTICAS}

CONFLITOS DE INTERESSE: Os autores declaram não possuir conflitos de interesse.

SUPORTE FINANCEIRO: O presente trabalho não foi suportado por nenhum subsídio ou bolsa.

PROVENIÊNCIA E REVISÃO POR PARES: Não comissionado; revisão externa por pares.

\section{ETHICAL DISCLOSURES}

CONFLICTS OF INTEREST: The authors have no conflicts of interest to declare.

FINANCIAL SUPPORT: This work has not received any contribution grant or scholarship.

PROVENANCE AND PEER REVIEW: Not commissioned; externally peer reviewed.

\section{REFERÊNCIAS}

1. Mézières F. La révolution en gymnastique orthopédique. Paris: Vuibert; 1949.

2. Souchard Ph-E. Le champs clos. Paris: Maloine; 1981.

3. Coelho L. O anti-fitness ou o manifesto anti-desportivo. Introdução ao conceito de reeducação postural. Quinta do Conde: Contra-Margem; 2008.

4. Bobath B. Adult hemiplegia. Amsterdam: Elsevier Health Sciences; 1970.

5. Bacon F. Novum organum. Porto: Rés; 1620.

6. Coelho L. Mézières' method and muscular chains' theory: from postural re-education's physiotherapy to anti-fitness concept. Acta Reumatol Port. 2010;35:406-7.

7. Coelho L. Raquialgias: Modelos fisioterapêuticos e preventivos. Gazeta Médica. 2020;7:313-4. 